\title{
RESÍDUOS DE ANTIMICROBIANOS DE USO VETERINÁRIO EM SOPINHAS DESTINADAS A LACTENTES E CRIANÇAS DE PRIMEIRA INFÂNCIA
}

\author{
Rosana Gomes Ferreira; Jônatas Vieira Grutes; Mararlene Ulberg Pereira; Mychelle Alves
} Monteiro; Felipe Stanislau Candido; Bernardete Ferraz Spisso

(rosana.ferreira@ incqs.fiocruz.br)

Instituto Nacional de Controle de Qualidade em Saúde, Fundação Oswaldo Cruz (INCQS/Fiocruz), Brasil

O uso de antimicrobianos na medicina veterinária pode deixar resíduos nos alimentos e a exposição humana desses resíduos pela dieta pode representar um risco à saúde dos consumidores. Lactentes e crianças de primeira infância são extremamente suscetíveis fisiologicamente a efeitos adversos devido a resíduos químicos em alimentos. O documento CODEX STAN 73-1981 do Codex Alimentarius Commission e a Portaria N ${ }^{\circ}$ 34/1998 da Anvisa estabelece que alimentos de transição para lactentes e crianças de primeira infância devem ser isentos de hormônios e antimicrobianos, e praticamente livres de outros contaminantes e de substâncias farmacologicamente ativas. Embora esta portaria descreva que resíduos de antibióticos não podem estar presentes nos alimentos destinados ao público infantil, ainda não há dados nacionais a respeito. A Organização Mundial de Saúde considera os macrolídeos (MC) como antimicrobianos criticamente importantes para o estabelecimento de políticas para minimizar os efeitos da resistência antimicrobiana. Atualmente, os produtos veterinários à base de MC estão autorizados no Brasil para bovinos, suínos, aves, ovinos e caprinos. O objetivo desse trabalho é estabelecer um método analítico que possa determinar a presença resíduos de MC (claritromicina, eritromicina, espiramicina, oleandomicina, tilmicosina, tilosina e troleandomicina) em sopinhas destinadas a lactentes e crianças de primeira infância. Diversos testes foram realizados no laboratório variando-se a forma de extração para o preparo de amostra a fim de se obter o método com melhores recuperações e maior praticidade. Uma extração simples e efetiva foi estabelecida utilizando método QuEChERS (Quick, Easy, Cheap, Effective, Rugged, Safe) para a preparação da amostra. A técnica utilizada para identificação e confirmação dos analitos foi a cromatografia líquida acoplada à espectrometria de massas sequencial (LC-MS/MS) com ionização por eletrospray positivo e modo de aquisição de monitoramento de reações múltiplas. Recuperações satisfatórias dos analitos foram obtidas (68-103\%). O método desenvolvido mostrou-se adequado para a análise de diferentes tipos de sopinhas, uma vez que não foi observado efeito de matriz relativo (RSD $\leq 9 \%$ ) em função da composição diferente de cada matriz. A estimativa de limite de detecção alcançou valores adequados $(0,02-4,12 \mu \mathrm{g} / \mathrm{kg})$. O método estabelecido, após validado, pode ser utilizado como uma ferramenta para avaliar o risco de exposição a resíduos de MC em alimentos para bebês e crianças.

Palavras-chave: antimicrobianos, macrolídeos, sopinhas. 